\title{
CHONDROGENIC DIFFERENTIATION OF HUMAN BONE MARROW-DERIVED MESENCHYMAL STEM CELLS IN A SIMULATED OSTEOCHONDRAL ENVIRONMENT IS HYDROGEL DEPENDENT
}

\author{
Marloes L. de Vries-van Melle ${ }^{1}$, Maria S.Tihaya ${ }^{1}$, Nicole Kops ${ }^{1}$, Wendy J.L.M. Koevoet ${ }^{2}$, J. Mary Murphy ${ }^{3}$, \\ Jan A.N. Verhaar ${ }^{1}$, Mauro Alini ${ }^{4}$, David Eglin ${ }^{4}$ and Gerjo J.V.M. van Osch ${ }^{1,2, *}$ \\ ${ }^{1}$ Department of Orthopaedics, Erasmus MC, University Medical Centre Rotterdam, The Netherlands \\ ${ }^{2}$ Department of Otorhinolaryngology, Erasmus MC, University Medical Centre Rotterdam, The Netherlands \\ ${ }^{3}$ Regenerative Medicine Institute, National Centre for Biomedical Engineering Science and School of Medicine, \\ Nursing and Health Sciences, National University of Ireland Galway, Ireland \\ ${ }^{4} \mathrm{AO}$ Research Institute, Davos, Switzerland
}

\begin{abstract}
Hydrogels pose interesting features for cartilage regeneration strategies, such as the option for injectability and in situ gelation resulting in optimal filling of defects. We aimed to study different hydrogels for their capability to support chondrogenesis of human bone marrow-derived mesenchymal stem cells (hBMSCs). hBMSCs were encapsulated in alginate, alginate with hyaluronic acid (alginate/HA), fibrin or thermoresponsive HA grafted with poly(N-isopropyl acrylamide) side-chains (HA-pNIPAM). Glycosaminoglycan production and cartilage-related gene expression were significantly higher in hBMSCalginate and hBMSC-fibrin constructs than in the other constructs. Supplementation of alginate with $\mathrm{HA}$ was not beneficial. hBMSC-alginate, hBMSC-fibrin and hBMSCHA-pNIPAM constructs were placed in simulated defects in osteochondral biopsies and cultured in vitro for $28 \mathrm{~d}$. Biopsies containing hBMSC-alginate and hBMSC-fibrin were implanted subcutaneously in nude mice for 12 weeks. hBMSC-alginate constructs had significantly higher cartilage-related gene expression after $28 \mathrm{~d}$ of culture as well as significantly more safranin-O positive repair tissue after 12 weeks in vivo than hBMSC-fibrin constructs. Although initial experiments with hBMSC-hydrogel constructs suggested comparable results of hBMSC-alginate, hBMSCfibrin and hBMSC-HA-pNIPAM constructs, culture in the osteochondral biopsy model in vitro as well as in vivo revealed differences, suggests that chondrogenesis of hBMSCs in an osteochondral environment is hydrogeldependent.
\end{abstract}

Keywords: Cartilage tissue engineering; mesenchymal stem cells; alginate; fibrin; hyaluronic acid.

\footnotetext{
*Address for correspondence:

Prof. G.J.V.M. van Osch

Room Ee16.14

Dr. Molewaterplein 50

3000 CA Rotterdam

The Netherlands
}

Telephone Number: +31 107043661

FAX Number: +31 107044690

E-mail: g.vanosch@erasmusmc.nl

\section{Introduction}

The complexity of articular cartilage and its lack of selfrepair capacity are widely recognised and these features have resulted in an on-going quest to identify the optimal cell sources and biomaterials that can be used for cartilage regeneration purposes. Human bone marrow-derived mesenchymal stem cells (hBMSCs) are one of the potential cell sources based on their multipotency, their expandability in vitro and the possibility to use autologous cells to treat patients (Pittenger et al., 1999).

One of the prerequisites for hBMSCs to differentiate towards the chondrogenic lineage is that a $3 \mathrm{D}$ environment should be provided (Johnstone et al., 1998; Mackay et al., 1998; Yoo et al., 1998). Pellet culture is widely used as an in vitro study model for chondrogenesis of hBMSCs. However, for translation towards treatment of patients, pellet cultures may not suffice to produce relevantly-sized repair tissue to fill cartilage defects.

A large variety of biomaterials have been developed, among which are various hydrogels that function as cell carriers. A major advantage of hydrogels over more solid biomaterials is that they generally can be shaped to fit the defect, and in some cases even allow in situ gelation which can result in optimal filling of a cartilage defect (Hernandez et al., 2010; Johnstone et al., 2013).

The different properties of various hydrogels will influence cell behaviour. In this study, we have compared different hydrogels as carriers for hBMSCs in terms of viability of the cells and their capacity to enable chondrogenic differentiation: alginate, fibrin and hyaluronan-poly(N)-isopropylacrylamide (HA-pNIPAM), each having their specific favourable characteristics. Alginate is a biological hydrogel that is widely used as a cell carrier in in vitro studies (Hauselmann et al., 1992; Loeser et al., 1995). From previous studies, it is known that alginate is a suitable carrier for stem cells, allowing chondrogenesis under appropriate culture conditions (Ghidoni et al., 2008). Apart from this, alginate is already approved for clinical use for various purposes, which would make development of a treatment for cartilage defects involving alginate as a cell carrier a realistic option (Thomas, 2000; Orive et al., 2002; Almqvist et al., 2009; Basta et al., 2011; Rokstad et al., 2011). Fibrin is well known for its applications for regeneration of various tissues, among which are repair strategies for cartilage and bone (Ito et al., 2006; Haleem et al., 2010; 
Liao et al., 2011; Wu et al., 2012). As it allows vascular ingrowth (Ryu et al., 2005; Falanga et al., 2007), fibrin may represent a suitable cell carrier for the repair of osteochondral defects, that also require the repair of bone as well as cartilage. Another favourable feature of fibrin is that there is the possibility of autologous use with isolation of both fibrinogen and thrombin from blood.

HA-pNIPAM contains hyaluronic acid (HA), which is the natural backbone of proteoglycans in articular cartilage. HA is also present in the synovial fluid, where it has a lubrication function. It has been shown that intra-articular injections of HA can provide relief of symptoms in patients with knee osteoarthritis (Bellamy et al., 2006; Divine et al., 2007). Interestingly, HA plays an important role during early chondrogenesis in embryonic development; after initial deposition HA is degraded before further chondrogenesis takes place (Toole, 1997). This makes HA-based gels interesting candidates for cartilage tissue engineering purposes. HA-pNIPAM is an engineered thermo-reversible gel that behaves in a nonNewtonian way: at temperatures below $32{ }^{\circ} \mathrm{C}$ it is liquid and it gels when the temperature rises above $32{ }^{\circ} \mathrm{C}$. For this specific gel, azide pNIPAM side chains were grafted onto a propargyl derivative HA backbone using "click" chemistry, causing its thermo-reversible characteristics: at temperatures lower than $32^{\circ} \mathrm{C}$, the pNIPAM sidechains are in their extended, hydrophilic state, whereas they are in a coiled, hydrophobic state when the temperature rises above $32{ }^{\circ} \mathrm{C}$ (Mortisen et al., 2010; D'Este et al., 2012). The association of the hydrophobic domains causes the actual gelation of the material. This specific gel has been developed for future minimally invasive treatments allowing injection of the material followed by in situ gelation. So far, the HA-pNIPAM gel has been studied for possible use in nucleus pulposus tissue regeneration (Peroglio et al., 2012; Malonzo et al., 2013).

In the present study, hBMSC-hydrogel constructs were formed with alginate, fibrin and HA-pNIPAM. To study the possible beneficial effect of HA, hBMSC-alginate constructs were formed in which the alginate was enriched with additional high molecular weight HA. After verifying cell survival during culture in the four different hBMSChydrogel constructs, chondrogenic differentiation of hBMSCs in the constructs was assessed. The addition of HA to alginate appeared not to have a favourable effect on chondrogenesis of hBMSCs. hBMSC-alginate, hBMSCfibrin and hBMSC-HA-pNIPAM constructs were cultured in an osteochondral biopsy model that can be used to mimic a joint-like environment in vitro. In this culture system, the addition of transforming growth factor $\beta$ (TGF $\beta$ ) to chondrogenic differentiation medium is not required, since factors released from the system itself are able to induce chondrogenesis of hBMSCs (de Vries-van Melle et al., 2013). We observed that culture of all hBMSChydrogel constructs in this osteochondral environment resulted in chondrogenesis in terms of cartilage-related gene expression. Due to the experimental nature of the HA-pNIPAM production process, total removal of copper catalyst remnants cannot yet be ensured. Therefore, hBMSC-alginate and hBMSC-fibrin constructs were selected for an in vivo experiment to validate in vitro results. These constructs were placed in the simulated cartilage defects in osteochondral biopsies, which were then placed subcutaneously in nude mice for 12 weeks. It was found that hBMSC-alginate constructs resulted in significantly more cartilaginous repair tissue than hBMSCfibrin constructs.

\section{Materials and Methods}

\section{hBMSC isolation and expansion}

All procedures for the collection of bone marrow from three healthy male donors of 22, 20 and 22 years of age have been approved by the Clinical Research Ethical Committee at University College Hospital, Galway, Ireland (Ref: 2/08) and by the institutional National University of Ireland Galway Research Ethics Committee (reference: 08/May/14). hBMSCs were isolated based on their plastic adherence. Heparinised bone marrow aspirates were seeded at a density of 2-5 x $10^{5}$ cells $/ \mathrm{cm}^{2}$ in hBMSC expansion medium consisting of Minimum Essential Medium-alpha (MEM- $\alpha$, Gibco, Carlsbad, CA, USA) supplemented with $10 \%$ foetal bovine serum (FBS, Lonza, Verviers, Belgium), $50 \mu \mathrm{g} / \mathrm{mL}$ gentamicine (Gibco) and $1.5 \mu \mathrm{g} / \mathrm{mL}$ fungizone (Gibco), $1 \mathrm{ng} / \mathrm{mL}$ fibroblast growth factor 2 (FGF2, AbD Serotec, Kidlington, UK) and $25 \mu \mathrm{g} / \mathrm{mL}$ ascorbic acid2-phosphate (Sigma-Aldrich, St. Louis, MO, USA). To remove non-adherent cells, medium was refreshed after $3 \mathrm{~d}$ and cells were washed after $5 \mathrm{~d}$ and adherent cells were further cultured. At subconfluence, hBMSCs were trypsinised and replated at a density of 2,300 cells $/ \mathrm{cm}^{2}$. hBMSC expansion medium was refreshed twice per week. Passage 3 or 4 hBMSCs were used for experiments.

\section{hBMSC-hydrogel constructs}

To create hBMSC-alginate constructs or hBMSC-alginate constructs enriched with HA, from now on referred to as hBMSC-alginate/HA constructs, hBMSCs were resuspended in $1.2 \%$ low viscosity alginate (Keltone, San Diego, CA, USA) or in $1.2 \%$ low viscosity alginate supplemented with $1 \%$ high molecular weight HA (1.5 MDa, Contipro Biotech s.r.o., Doulny Dobrouc, Czech Republic) in physiological saline at a density of $10 \times 10^{6}$ cells/mL. The alginate-cell suspension or alginate/HA cell suspension was pressed through a 22 gauge needle into $102 \mathrm{mM} \mathrm{CaCl}_{2}$. Constructs were washed twice in physiological saline and once in incomplete chondrogenic differentiation medium (ICM) consisting of Dulbecco's Modified Eagle Medium with glutamax (DMEM, Gibco) supplemented with insulin, transferrin and selenium, serum replacement (ITS $+1, \mathrm{~B} \& \mathrm{D}$ Bioscience, Bedford, MA, USA), $40 \mu \mathrm{g} / \mathrm{mL}$ L-proline (Sigma-Aldrich), $1 \mathrm{mM}$ sodium pyruvate (Gibco), $1.5 \mu \mathrm{g} / \mathrm{mL}$ fungizone (Gibco), $50 \mu \mathrm{g} / \mathrm{mL}$ gentamicin (Gibco), $25 \mu \mathrm{g} / \mathrm{mL}$ ascorbic acid-2phosphate and $10^{-7} \mathrm{M}$ dexamethasone (Sigma-Aldrich). When $10 \mathrm{ng} / \mathrm{mL}$ TGF $\beta 1$ (R\&D Systems, Minneapolis, MA, USA) was added, the medium is referred to as complete chondrogenic medium (CCM). $100 \mu \mathrm{L}$ of medium was used per construct, 10 to 12 constructs were cultured per well in 24-well plates. 
To obtain a concentration of $10 \times 10^{6}$ cells $/ \mathrm{mL}$ in hBMSC-fibrin constructs, hBMSCs were suspended at a density of $20 \times 10^{6}$ cells $/ \mathrm{mL}$ in $40 \mathrm{mg} / \mathrm{mL}$ fibrinogen from human plasma (Sigma-Aldrich) to which $60 \mathrm{U} / \mathrm{mL}$ aprotinin (Sigma-Aldrich) was added to prevent early degradation of fibrin. hBMSC-fibrin constructs were created by pipetting $25 \mu \mathrm{L}$ of fibrinogen-cell suspension onto Teflon coated hydrophobic glass slides with wells $7 \mathrm{~mm}$ in diameter (Nutacon, Leimuiden, the Netherlands). An equal volume of $10 \mathrm{U} / \mathrm{mL}$ thrombin from human plasma (Sigma-Aldrich) in $40 \mathrm{mM} \mathrm{CaCl}_{2}$ was added to the fibrinogen-cell suspension. hBMSC-fibrin constructs were incubated for $15 \mathrm{~min}$ at $37{ }^{\circ} \mathrm{C}$ and $5 \% \mathrm{CO}_{2}$ after which medium was added and constructs were incubated for $30 \mathrm{~min}$. Subsequently, constructs were carefully removed from the glass slide using a spatula and 2 constructs were cultured in $1.5 \mathrm{~mL}$ chondrogenic or culture medium in 24-well plates.

hBMSCs were resuspended at a density of $10 \times 10^{6}$ cells $/ \mathrm{mL}$ in cold $17 \%$ HA-pNIPAM in phosphate-buffered saline (PBS) to create hBMSC-HA-pNIPAM constructs. HA-pNIPAM synthesis was reported elsewhere (D'Este et al., 2012). The HA-pNIPAM cell suspension was pipetted onto Teflon-coated hydrophobic glass slides that where heated to $42{ }^{\circ} \mathrm{C}$ and incubated at $42{ }^{\circ} \mathrm{C}$ for $5 \mathrm{~min}$. Glass slides with hBMSC-HA-pNIPAM constructs were transferred to PBS that was pre-heated to $37{ }^{\circ} \mathrm{C}$ and incubated at $37^{\circ} \mathrm{C}$ and $5 \% \mathrm{CO}_{2}$ for $10 \mathrm{~min}$. Subsequently, hBMSC-HA-pNIPAM constructs were carefully removed from the glass slide using a pre-heated spatula and 2 constructs were cultured in $1.5 \mathrm{~mL}$ pre-heated CCM in 24 wells plates.

Unless stated otherwise, hBMSC-hydrogel constructs were cultured for $28 \mathrm{~d}$ at $37{ }^{\circ} \mathrm{C}$ and $5 \% \mathrm{CO}_{2}$ in $\mathrm{CCM}$. hBMSC-alginate constructs in ICM served as negative controls. Medium was refreshed three times per week. After 28 d, hBMSC-hydrogel constructs were harvested for mRNA isolation or biochemical assays.

\section{Osteochondral culture model}

Cartilage defects were simulated in bovine osteochondral biopsies as described previously (de Vries-van Melle et al., 2012). In short, osteochondral biopsies of $8 \mathrm{~mm}$ in diameter were created using a hollow drill (Synthes, Oberdorf, Switzerland) from the four proximal sesamoid bones of fresh metacarpal phalangeal joints of 3 to 8 months old calves. After washing, the biopsies were cut to about $5 \mathrm{~mm}$ in length and sterility was verified by overnight incubation in DMEM supplemented with $10 \%$ FBS, $50 \mu \mathrm{g} / \mathrm{mL}$ gentamicin and $1.5 \mu \mathrm{g} / \mathrm{mL}$ fungizone. Using a $6 \mathrm{~mm}$ in diameter dermal biopsy punch (Stiefel Laboratories, Durham, NC, USA) and scalpel, cartilage was removed as well as the calcified cartilage layer and part of the subchondral plate, resulting in simulated osteochondral defects. To prevent outgrowth of cells from the subchondral bone, biopsies were placed in $2 \%$ lowgelling agarose (gelling temperature $37-39^{\circ} \mathrm{C}$, Eurogentec, Liege, Belgium) in physiological saline in such a way that the subchondral bone was surrounded by agarose and the cartilage was above the agarose surface.
To create hBMSCs-alginate constructs in the simulated osteochondral cartilage defects in the osteochondral culture model, hBMSCs were resuspended in $1.2 \%$ low viscosity alginate or in $1.2 \%$ low viscosity alginate supplemented with $1 \%$ high molecular weight HA in physiological saline at a density of $10 \times 10^{6}$ cells $/ \mathrm{mL}$. Simultaneously, $50 \mu \mathrm{L}$ of alginate cell suspension and $50 \mu \mathrm{L} 102 \mathrm{mM} \mathrm{CaCl}_{2}$ were pipetted into the simulated cartilage defects of subchondral nature, allowing the alginate to solidify inside the defects. To create hBMSC-fibrin or hBMSC-HA-pNIPAM constructs in simulated osteochondral defects, constructs were created as described above. After removal from the Teflon-coated glass slides, constructs were press-fitted into simulated osteochondral defects. Unless stated otherwise, osteochondral biopsies with hBMSC-hydrogel constructs were cultured for $28 \mathrm{~d}$ at $37{ }^{\circ} \mathrm{C}$ and $5 \% \mathrm{CO}_{2}$ in $1.5 \mathrm{~mL}$ ICM per biopsy. Medium was refreshed three times per week. Used medium was stored once per week at $-80{ }^{\circ} \mathrm{C}$ for later analysis. After $28 \mathrm{~d}$, hydrogel constructs were harvested for mRNA isolation or biochemical assays.

\section{mRNA isolation and qRT-PCR}

After $28 \mathrm{~d}$ of culture, hBMSC-alginate and hBMSCalginate/HA constructs were dissolved using $150 \mu \mathrm{L} /$ construct $55 \mathrm{mM}$ sodium citrate in $20 \mathrm{mM}$ ethylene diaminotetraacetate (EDTA, Sigma). hBMSC-alginate constructs cultured in the osteochondral model were removed using a spatula and dissolved in $450 \mu \mathrm{L}$ sodium citrate in EDTA. Samples were incubated at $4{ }^{\circ} \mathrm{C}$ while rotating and subsequently centrifuged for $8 \mathrm{~min}$ at $1,200 \mathrm{rpm}$ to remove all alginate remains. The supernatant was removed and the samples were resuspended in $150 \mu \mathrm{L} /$ construct or $500 \mu \mathrm{L} /$ sample RNABee (TEL-TEST, Friendswood, TX, USA). hBMSC-fibrin constructs were either transferred from 24-well plates or removed from simulated osteochondral defects, into $500 \mu \mathrm{L}$ RNABee and crushed manually. hBMSC-HA-pNIPAM constructs were transferred from 24-well plates using a pre-heated spatula and were dissolved in cold PBS, centrifuged at 1,200 rpm for $8 \mathrm{~min}$ and the resulting cell pellet was resuspended in $500 \mu \mathrm{L}$ RNABee. Chloroform was added to all samples at a quantity of $200 \mu \mathrm{L} / \mathrm{mL}$ RNABee. Further RNA isolation was performed using the RNeasy Microkit (Qiagen, Hilden, Germany) according to the manufacturer's instructions, including on-column DNAse treatment. RNA concentration and quality was measured using a NanoDrop ND1000 UV-VIS spectrophotometer (Isogen Life Science B.V., de Meern, the Netherlands). cDNA was prepared using RevertAid First Strand cDNA Synthesis Kit (MBI Fermentas, St. Leon-Rot, Germany) according to the manufacturer's instructions. qRT-PCR was performed in $20 \mu \mathrm{L}$ reactions on a ABI Prism 7000 system (Applied Biosystems, Foster City, CA, USA) using either Taqman Universal PCR mastermix (Applied Biosystems) or SybrGreen (Eurogentec). The expression of the cartilage-related genes collagen type 2 (Col2) and aggrecan $(A C A N)$ and the hypertrophy-related genes collagen type $\mathrm{X}(\operatorname{ColX})$ and alkaline phosphatase $(A L P L)$ was determined (Farrell et al., 2009; Clockaerts et al., 2011). Glyceraldehyde-3-phosphate dehydrogenase (GAPDH) 
was selected as reference gene after comparison with two other housekeeping genes (data not shown) (Farrell et al., 2009). Relative gene expression was calculated using the $2^{-\Delta \mathrm{CT}}$ method (Schmittgen and Livak, 2008).

\section{Glycosaminoglycan content and DNA assays}

After $28 \mathrm{~d}$ of culture, hBMSC-alginate, hBMSC-alginate/ HA and hBMSC-HA-pNIPAM constructs were dissolved in $55 \mathrm{mM}$ sodium citrate in $20 \mathrm{mM}$ EDTA. hBMSC-fibrin constructs were crushed manually in the same solution. Subsequently, all samples were digested overnight at $56{ }^{\circ} \mathrm{C}$ in $200 \mu \mathrm{g} / \mathrm{mL}$ papain in $50 \mathrm{mM}$ EDTA supplemented with $5 \mathrm{mM}$ L-cysteine (Sigma-Aldrich). The amount of sulphated glycosaminoglycan (GAG) was determined using the dimethylmethylene blue (DMB) assay in which the protocol was modified for measurement in alginate: the $\mathrm{pH}$ of the DMB reagent was lowered to 1.75 using formic acid (Farndale et al., 1982; Enobakhare et al., 1996). A spectrophotometer (VersaMax, Molecular Devices, Sunnyvale, CA, USA) was used to measure the metachromatic reaction of GAGs with DMB at 540 and $595 \mathrm{~nm}$. Chondroitin sulphate C (Sigma-Aldrich) was used as a standard. The DNA content in papain-digested samples was determined after RNAse (Sigma-Aldrich) treatment using ethidium bromide (Gibco). Using a spectrofluorometer (Wallac 1420 Victor 2, Perkin-Elmer, Wellesley, MA, USA), the extinction and emission were measured at $340 \mathrm{~nm}$ and $590 \mathrm{~nm}$, respectively. Calf thymus DNA (Sigma-Aldrich) was used as a standard.

\section{In vivo implantation of osteochondral biopsies}

hBMSC-alginate and hBMSC-fibrin constructs were created in simulated osteochondral defects as described above using passage $3 \mathrm{hBMSCs}$ from three different donors. The hBMSC-hydrogel constructs in the simulated defects were cultured overnight to allow stabilisation of the system and to verify sterility. Four osteochondral biopsies per mouse were implanted subcutaneously in female NMRI nu/nu mice (Charles River, Wilmington, MA, USA) under isoflurane anaesthesia. The simulated defects in the osteochondral biopsies were covered using an $8 \mathrm{~mm}$ diameter Neuro-Patch membrane (Braun, Melsungen, Germany) to prevent ingrowth of host tissue. Before and 6-10 $\mathrm{h}$ after surgery, mice received $0.05 \mathrm{mg} / \mathrm{kg}$ bodyweight of Temgesic (Reckitt Bensicker, Slough, UK). During surgery, mice received $9 \mathrm{mg} / \mathrm{kg}$ bodyweight of Ampi-dry (Dopharma, Raamsdonksveer, the Netherlands). After 12 weeks, mice were euthanised by cervical dislocation. Osteochondral biopsies with hBMSC-hydrogel constructs were carefully explanted and fixed in $4 \%$ formalin. After at least 1 week of fixation, samples were decalcified using $10 \%$ formic acid (Sigma-Aldrich) for three weeks. Subsequently, biopsies were embedded in paraffin, sectioned in $6 \mathrm{~mm}$ sections and subjected to histology. All animal experiments were conducted with approval of the local animal ethical committee (EMC2353, protocol number 116-11-06).

\section{Histology and quantification}

After sections were deparaffinised and rehydrated, safranin-O staining was performed to visualise glycosaminoglycans in the extracellular matrix and haematoxylin and eosin staining was performed to visualise general morphology. For safranin-O staining, slides were first stained with $0.1 \%$ light green for $8 \mathrm{~min}$, subsequently washed in $1 \%$ acetic acid and stained with $0.1 \%$ safranin-O (Fluka, St. Gallen, Switzerland) for $12 \mathrm{~min}$. The cross-sectional area of the simulated cartilage defect was measured and the cross-sectional area of newly formed safranin-O positive tissue was determined using ImageJ software (National Institutes of Health, Bethesda, MA, USA). These measurements were performed on three sections of all osteochondral biopsies that were implanted subcutaneously. Newly formed tissue was discriminated visually from native cartilage. The presence or absence of bone formation in simulated defects was scored based on tissue morphology.

\section{Immunohistochemistry}

Immunohistochemical staining was performed for collagen type 2. To allow the use of mouse monoclonal antibodies, the primary and secondary antibodies were coupled before use. The primary antibody for collagen type 2 (II-II6B3, $0.4 \mu \mathrm{g} / \mathrm{mL}$, Developmental Studies Hybridoma Bank, Iowa City, IA, USA) was coupled overnight with a biotinylated goat-anti-mouse IgG antibody (Jackson Laboratories, Bar Harbor, ME, USA) followed by $2 \mathrm{~h}$ incubation in $0.1 \%$ normal mouse serum (CLB, Amsterdam, the Netherlands). After sections were deparaffinised and rehydrated, antigen retrieval was performed by incubation for $30 \mathrm{~min}$ at $37{ }^{\circ} \mathrm{C}$ in $0.1 \%$ pronase (Sigma-Aldrich) in PBS. Subsequently, slides were incubated for $30 \mathrm{~min}$ at $37{ }^{\circ} \mathrm{C}$ in $1 \%$ hyaluronidase (Sigma-Aldrich) in PBS. Blocking for non-specific binding was performed using $10 \%$ goat serum (Sigma-Aldrich) in PBS. Slides were incubated overnight at $4{ }^{\circ} \mathrm{C}$ with the coupled primary and secondary antibody or the negative mouse IgG control antibody (Serotec Ltd, Oxford, UK) in PBS containing $1 \%$ bovine serum albumin (PBS/BSA). Slides were incubated with enzyme-streptavidin conjugate (Label, HK-321-UK, Biogenex, Fremount, CA, USA) diluted 1:100 in PBS/BSA and subsequently incubated with Neu Fuchsin substrate (Chroma, Kongen, Germany).

\section{Statistical analysis}

Normality was verified using Kolmogorov-Smirnov and Shapiro-Wilk normality tests using SPSS 15.0. When necessary, logarithmic transformation was performed to obtain normal distribution of the data. Student's $t$-test was used to analyse unpaired data. A generalised estimated equations model was used for paired data that was normally distributed. For paired data that was not normally distributed, Kruskal-Wallis test was performed, followed by the Mann Whitney U test. False discovery rate was used to correct for multiple testing. For all statistical analyses, differences were considered statistically significant at $p<0.05$. 
A

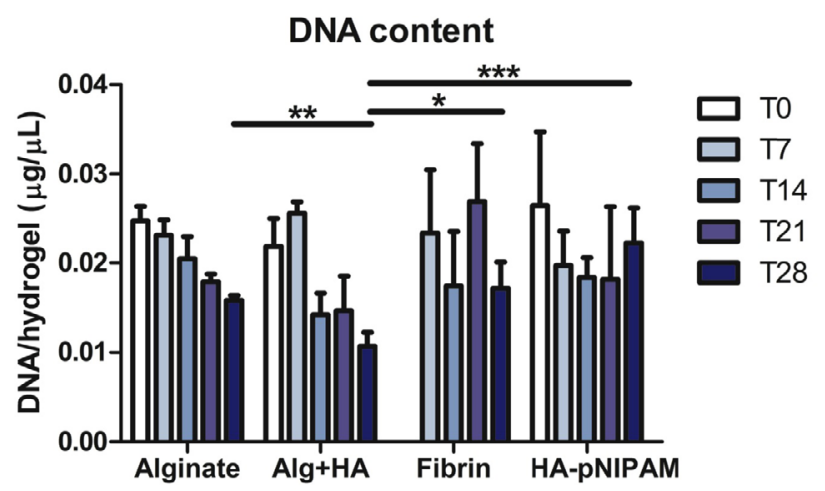

B

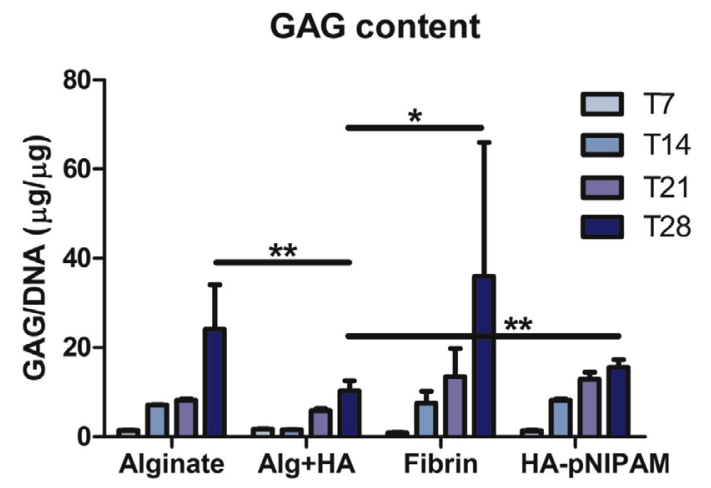

C
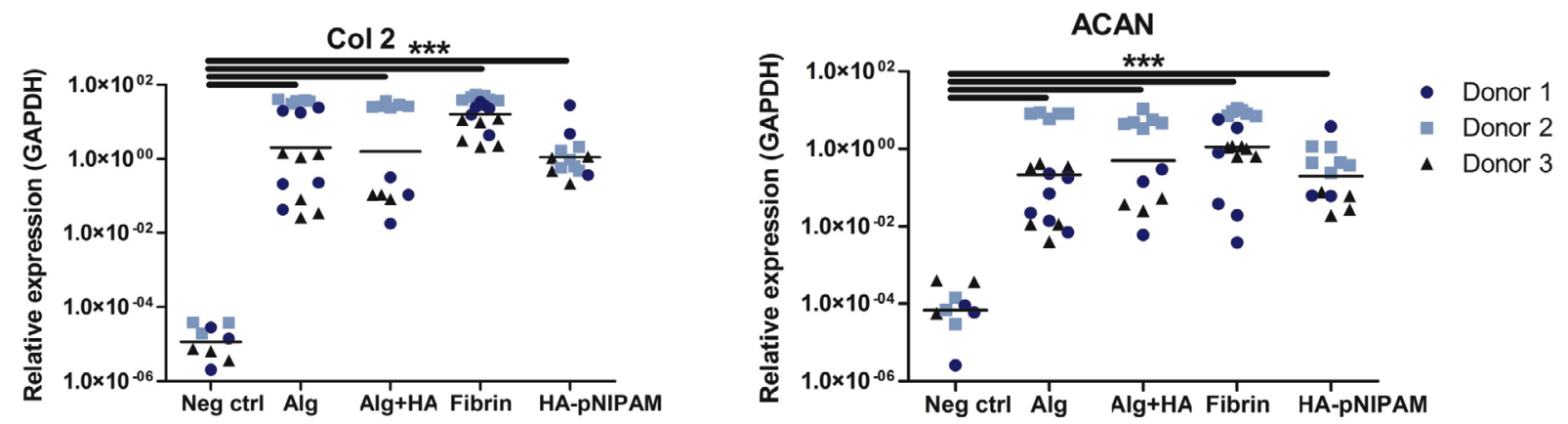

Fig. 1. Alginate, fibrin and HA-pNIPAM support chondrogenesis of hBMSCs. hBMSCs were cultured in complete chondrogenic medium up to $28 \mathrm{~d}$. hBMSC-alginate constructs cultured in incomplete chondrogenic medium served as negative controls. A. DNA quantification of hBMSC-hydrogel constructs cultured up to $28 \mathrm{~d}$. hBMSCs from 1 donor, $n=6$. B. GAG quantification per DNA of hBMSC-hydrogel constructs cultured up to $28 \mathrm{~d}$. hBMSCs from 1 donor, $n=6$. C. Col2 and $A C A N$ gene expression relative to GAPDH of hBMSC-hydrogel constructs cultured for $28 \mathrm{~d}$. hBMSCs from 3 different donors, $n=6$ per donor, negative controls $n=3$ per donor. Means are represented with standard deviations. Student's $t$-test (A and B) or a generalised estimated equations model on log-transformed data to obtain normally distributed data (C) was used. $* p<0.05, * * p<0.01, * * * p<0.001$.

Fig. 2. (see next page - page 117) Alginate, and not fibrin, favours Col2 expression in vitro and chondrogenesis of hBMSCs in an osteochondral environment in vivo. A. Gene expression of Col2 and ACAN relative to GAPDH of hBMSC-hydrogel constructs cultured in incomplete chondrogenic medium in simulated cartilage defects in an osteochondral biopsy model for $28 \mathrm{~d}$. Negative controls: hBMSC-alginate constructs in incomplete chondrogenic medium without osteochondral biopsy. For alginate and fibrin: hBMSCs from 3 donors, $n=3$ per donor; for HApNIPAM: hBMSCs from 1 donor, $n=3$. B,C. Representative safranin-O stained sections of hBMSC-alginate (B), hBMSC-fibrin (C) constructs in simulated cartilage defects in an osteochondral biopsy model that were implanted subcutaneously in nude mice for 12 weeks. hBMSCs from 3 donors, $n=3$ per donor. D. Control alginate construct without hBMSCs. Scale bars indicate $3 \mathrm{~mm}$ (left images) or $800 \mu \mathrm{m}$ (insets). E. Quantification of subcutaneously implanted hBMSC-alginate and hBMSC-fibrin constructs in simulated cartilage defects in an osteochondral biopsy model. hBMSCs from 3 donors, $n=3$ per donor. Generalised estimated equations model on log transformed data to obtain normally distributed data. $* p<0.05$, $* * p<0.01$, $* * * p<0.001$. F. Representative collagen type 2 immunostained sections of hBMSC-alginate constructs in simulated cartilage defects in an osteochondral biopsy model that was implanted subcutaneously in nude mice for 12 weeks. Scale bars indicate $3 \mathrm{~mm}$ (left image) or $800 \mu \mathrm{m}$ (inset). SB: subchondral bone, NC: native cartilage, M: Neuro-Patch membrane, NT: newly formed tissue, FT: fibrous tissue.

\section{Results}

All four hydrogels support chondrogenesis of hBMSCs hBMSC-hydrogel constructs were cultured up to $28 \mathrm{~d}$ in $\mathrm{CCM}$ and DNA content was determined at various time points as a measure of hBMSC survival. In alginate and
alginate/HA constructs, DNA content decreased with time, whereas in fibrin and HA-pNIPAM this was not as evident (Fig. 1A). hBMSC-alginate/HA constructs cultured for $28 \mathrm{~d}$ contained significantly less DNA than hBMSCalginate $(p=0.006)$, hBMSC-fibrin $(p=0.03)$ or hBMSCHA-pNIPAM $(p=0.009)$ constructs. No differences were 

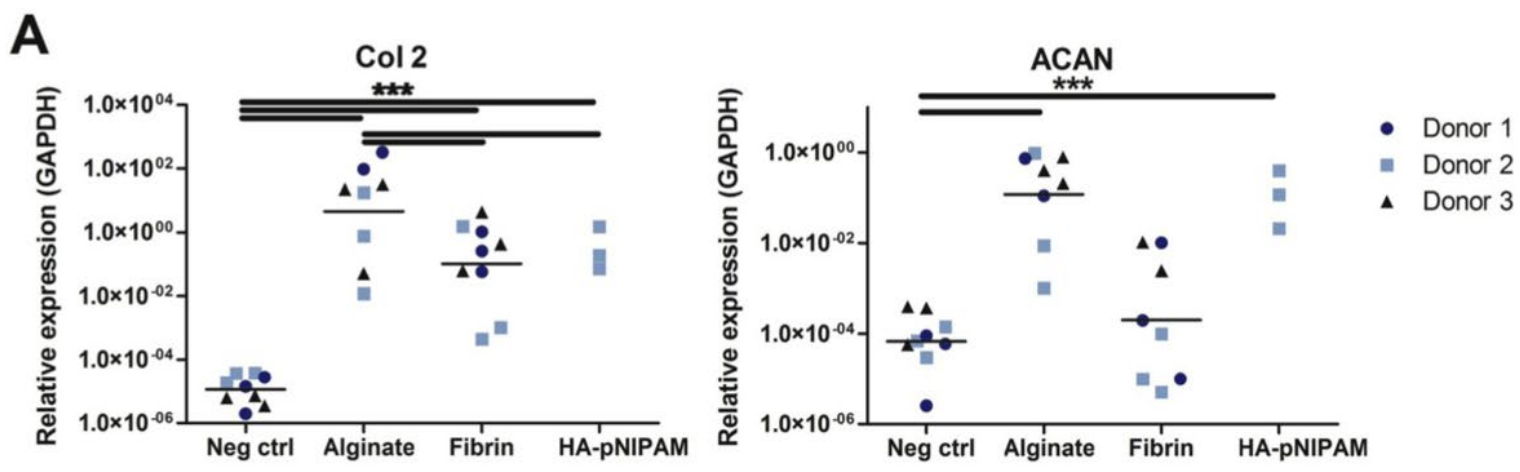

B

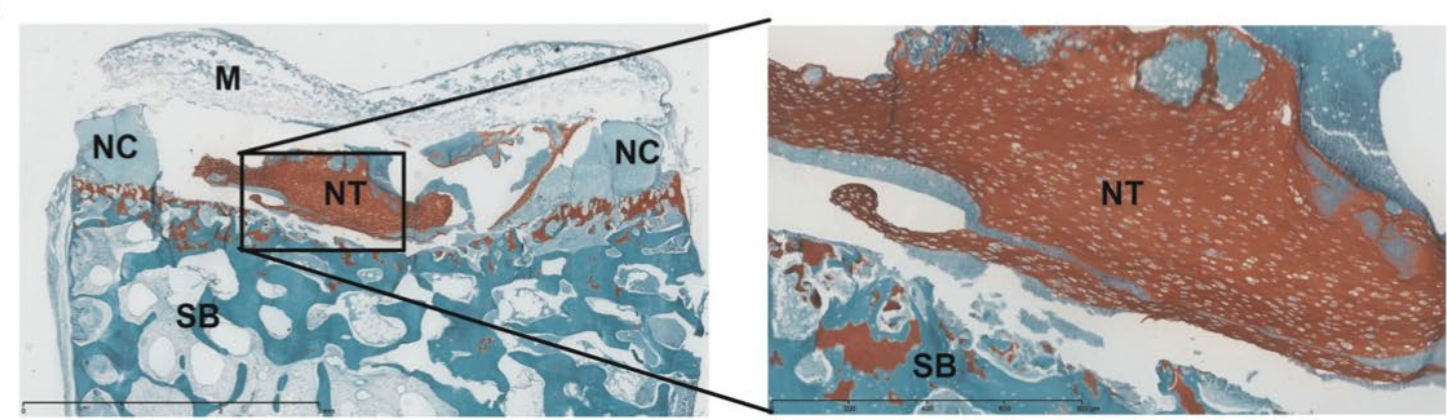

C

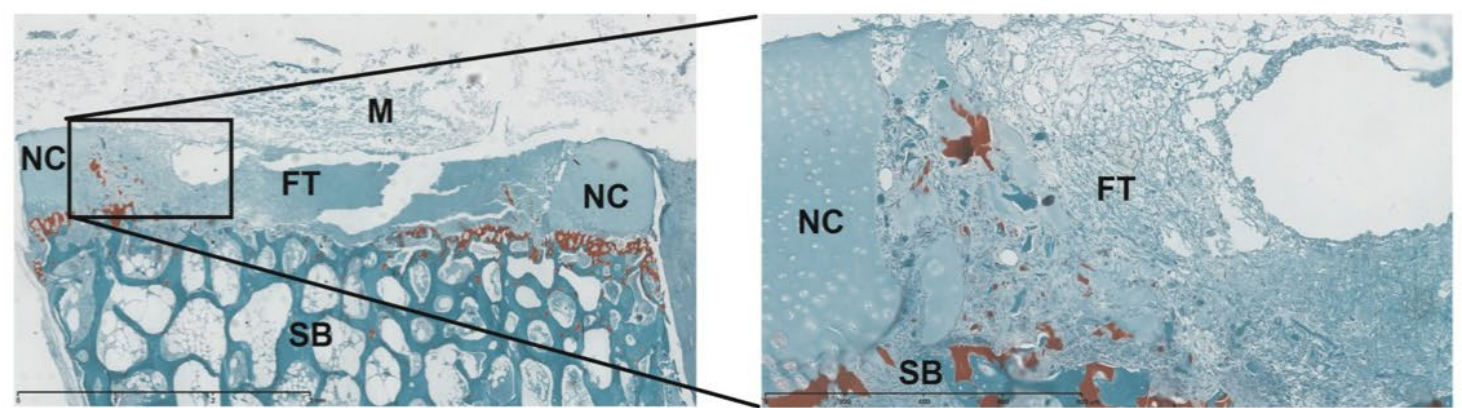

D

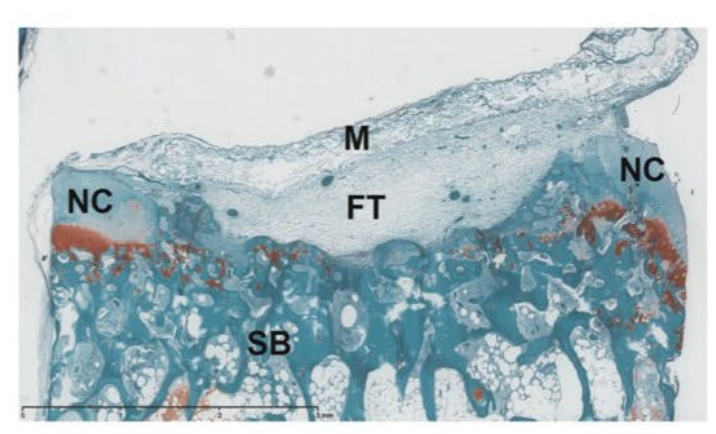

E

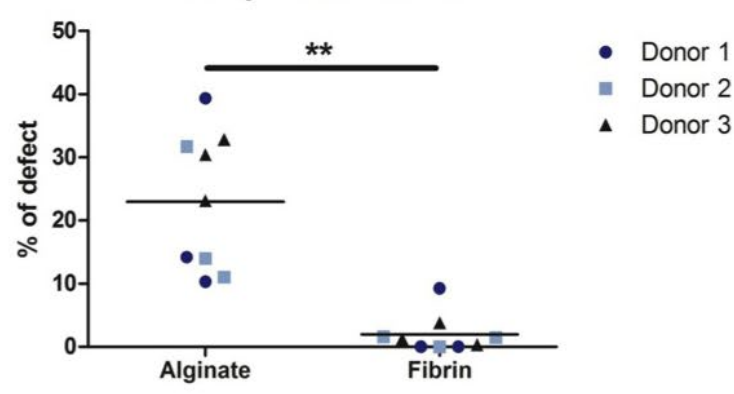

F

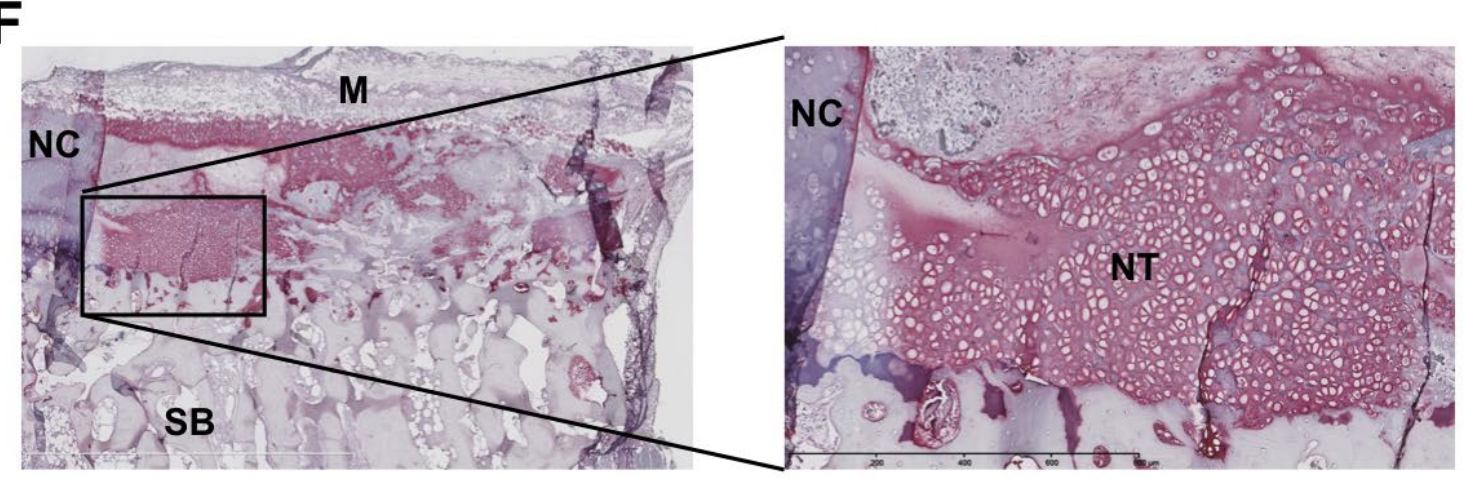


A

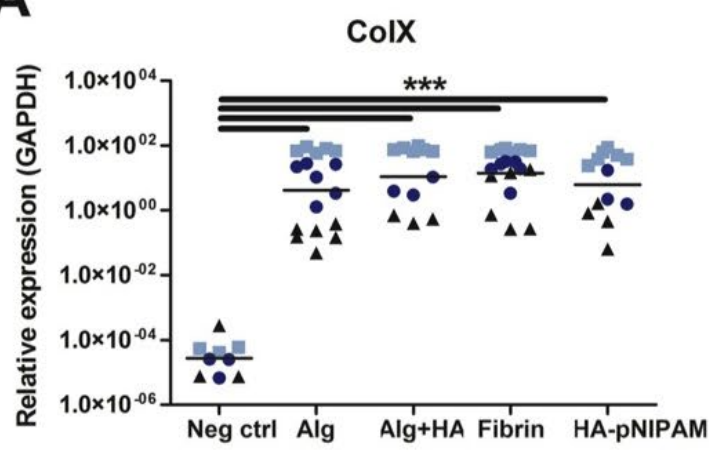

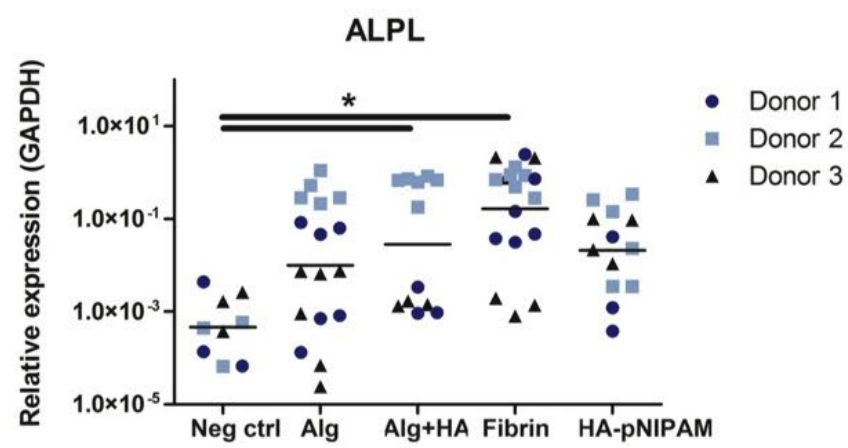

B
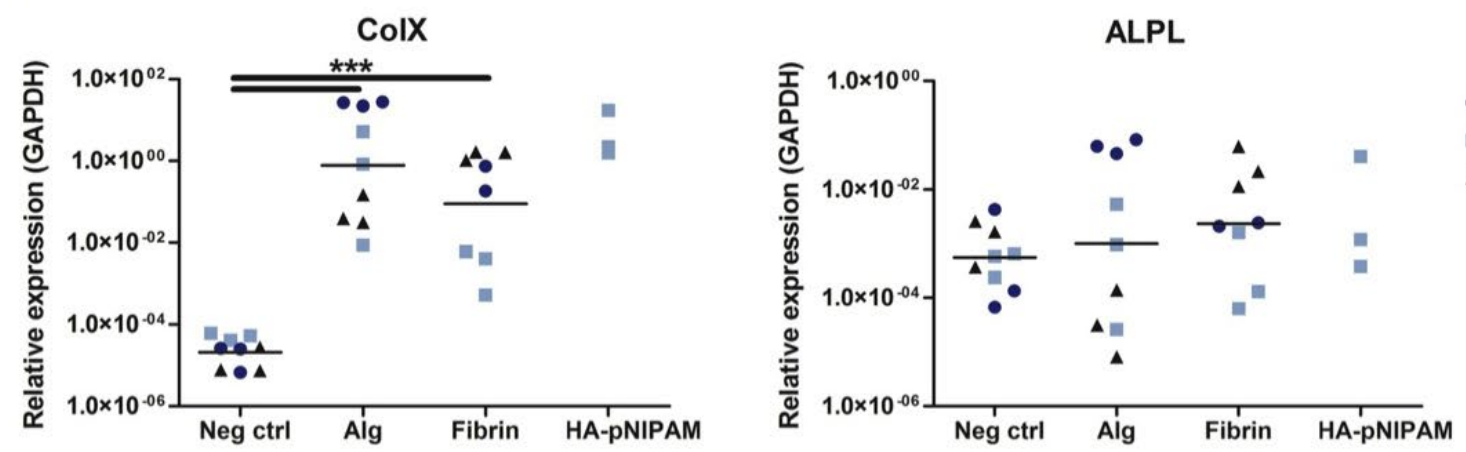

- Donor 1

- Donor 2

- Donor 3

C

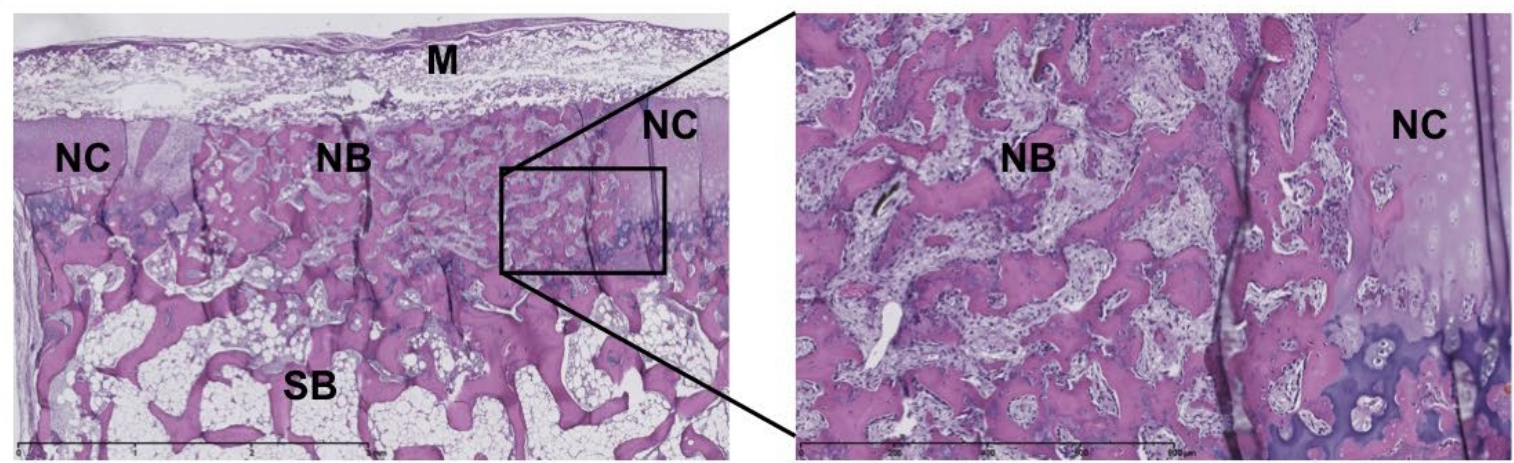

D

\begin{tabular}{|c|c|c|c|c|c|c|c|c|c|c|}
\hline & \multicolumn{3}{|c|}{ MSC donor 1} & \multicolumn{3}{|c|}{ MSC donor 2} & \multicolumn{3}{|c|}{ MSC donor 3} & \\
\hline & $\overline{\mathrm{m} 1}$ & $\mathrm{~m} 2$ & $\mathrm{~m} 3$ & m1 & $\mathrm{m} 2$ & $\mathrm{~m} 3$ & $\mathrm{~m} 1$ & $\mathrm{~m} 2$ & $\overline{\mathrm{m}^{3}}$ & \\
\hline alginate & & & 1 & & & & & & & 1 \\
\hline fibrin & & & & & 1 & & 1 & 1 & 1 & 4 \\
\hline & & 1 & & & 1 & & & 3 & & \\
\hline
\end{tabular}

Fig. 3. Bone formation in vivo appears less frequent in alginate than in fibrin. A,B. ColX and $A L P L$ gene expression relative to GAPDH of hBMSC-hydrogel constructs cultured in complete chondrogenic medium (A) or in incomplete chondrogenic medium in simulated cartilage defects in osteochondral biopsies (B). hBMSCs from 3 different donors, $n=6$ (A) or $n=3$ (B) per donor. Negative controls: hBMSC-alginate constructs in incomplete chondrogenic medium without osteochondral biopsies. Generalised estimated equations model on log transformed data to obtain normally distributed data. ${ }^{*} p<0.05,{ }^{* *} p<0.01, * * * p<0.001$. C. Representative haematoxylin and eosin stained sections of hBMSC-fibrin constructs in simulated cartilage defects implanted subcutaneously in nude mice for 12 weeks in which bone formation was observed. SB: subchondral bone, NC: native cartilage, M: Neuro-Patch membrane, NT: newly formed tissue, FT: fibrous tissue. Scale bars indicate $3 \mathrm{~mm}$ (left image) or $800 \mu \mathrm{m}$ (inset). D. Scoring of the presence of bone formation by hBMSC-alginate or hBMSC-fibrin constructs in simulated cartilage defects implanted subcutaneously in nude mice for 12 weeks. hBMSCs from 3 donors, $n=3$ per donor. $\mathrm{m} \#$ indicate the individual mice. 
observed in terms of DNA content after $28 \mathrm{~d}$ of culture between hBMSC-alginate, hBMSC-fibrin and hBMSCHA-pNIPAM constructs.

Chondrogenic differentiation of hBMSC-hydrogel constructs cultured for $28 \mathrm{~d}$ in CCM was assessed by means of GAG content (Fig. 1B) and cartilage related gene expression (Fig. 1C). GAG content normalised to DNA content was determined in hBMSC-hydrogel constructs after $28 \mathrm{~d}$ of culture. In hBMSC-alginate/HA constructs, significantly less GAG per DNA was observed than in hBMSC-alginate $(p=0.008)$, hBMSC-fibrin $(p=0.044)$ or hBMSC-HA-pNIPAM ( $p=0.001)$ constructs (Fig. 1B). To verify whether deposited GAGs were potentially released from the hBMSC-hydrogel constructs into the medium, the GAG content of medium in which hBMSC-hydrogel constructs were cultured for $3 \mathrm{~d}$ was measured at various time points during the experiment. No GAGs were detected in used culture medium of all hydrogels (data not shown).

Chondrogenic differentiation, evaluated by cartilage related gene expression was observed in hBMSCs from three different donors in constructs formed with all four hydrogels cultured for $28 \mathrm{~d}$ in CCM. Chondrogenic differentiation was not observed in negative controls consisting of hBMSC-alginate constructs cultured in ICM (Fig. 1C). The same was observed for the hBMSC-hydrogel constructs of the other hydrogels cultured in ICM (data not shown). No significant differences were observed between constructs from the different hydrogels cultured in CCM in terms of Col2 and ACAN gene expression. Since no beneficial effect of the addition of HA to alginate was observed on GAG production by hBMSCs, hBMSC-alginate/HA constructs were not used for further experiments.

\section{Alginate favours hBMSC chondrogenesis in an osteochondral environment in vivo}

hBMSC-hydrogel constructs formed with alginate, fibrin or HA-pNIPAM were cultured in simulated defects in osteochondral biopsies for $28 \mathrm{~d}$ in ICM (Fig. 2A). Significantly higher levels of Col2 gene expression were measured in hBMSC-alginate constructs than were measured in the other hBMSC-hydrogel constructs $(p<0.001)$. Due to the required temperature for creating and handling hBMSC-HA-pNIPAM constructs, we only managed to perform the experiment with hBMSC-HApNIPAM constructs with hBMSCs from one donor. For this reason and the fact that the use of HA-pNIPAM is not yet clinically relevant in its current form since total removal of copper catalyst remnants cannot yet be ensured, hBMSCalginate and hBMSC-fibrin constructs were selected for the in vivo experiment.

After 12 weeks of subcutaneous implantation in nude mice, hBMSC-alginate and hBMSC-fibrin constructs in simulated defects in osteochondral biopsies were explanted and subjected to histology. hBMSC-alginate constructs formed substantial amounts of tissue positive for safranin-O staining, indicating the presence of GAGs in the newly formed tissue (Fig. 2B). In hBMSC-fibrin constructs in simulated defects, hardly any safranin-O positive tissue was observed (Fig. 2C). This was reflected upon quantification of safranin-O positive repair tissue: significantly more safranin-O positive repair tissue was formed in hBMSC-alginate constructs in simulated defects (Fig. 2E). Immunostaining demonstrated corresponding deposition of collagen type 2 in $\mathrm{hBMSC}$-alginate constructs in simulated defects (Fig. 2F), whereas hardly any collagen type 2 positive tissue was observed in hBMSC-fibrin constructs (data not shown). In control defects, in which hydrogel constructs without hBMSCs were implanted, no safranin-O positive tissue was observed (Fig. 2D).

\section{Occasional bone formation in vivo was found in hBMSC-fibrin constructs}

A known characteristic of hBMSCs is that upon in vitro chondrogenesis, these cells tend to become hypertrophic, which ultimately leads to terminal differentiation characterised by mineralisation in vitro and bone formation in vivo (Pelttari et al., 2006; Scotti et al., 2010). Gene expression of the hypertrophy-related genes ColX and $A L P L$ were measured in hBMSC-hydrogel constructs cultured in CCM (Fig. 3A) or in simulated cartilage defects in the osteochondral biopsy model in ICM (Fig. 3B). No significant differences were observed in ColX or $A L P L$ gene expression between groups, apart from the negative controls consisting of hBMSC-alginate constructs cultured in ICM. Despite the expression of hypertrophic genes in vitro, bone formation was only observed occasionally after 12 weeks of subcutaneous implantation of hBMSChydrogel constructs in the osteochondral biopsy model (Fig. 3C). The presence of observed bone formation was scored (Fig. 3D). Bone formation was observed in one out of nine hBMSC-alginate constructs, whereas it was observed in four out of nine hBMSC-fibrin constructs. In all samples in which bone formation was observed, the newly formed bone filled the entire defect. The occasional bone formation was mainly observed in hBMSC-fibrin constructs involving hBMSCs from one specific donor. No bone formation was observed in control defects, i.e. alginate or fibrin without hBMSCs in simulated defects implanted subcutaneously in nude mice for 12 weeks.

\section{Discussion}

Alginate, fibrin and multiple HA-based biomaterials have been described for cartilage regeneration purposes in various settings and combinations (Itay et al., 1987; Hauselmann et al., 1992; Goa and Benfield, 1994; Ting et al., 1998; Park et al., 2011). We compared these materials directly for their capacity to support chondrogenesis of hBMSCs in an osteochondral environment for the first time. Although results of hBMSC-hydrogel constructs after conventional in vitro culture were comparable, chondrogenesis of hBMSCs in an osteochondral environment both in vitro and in vivo appeared to be hydrogel dependent.

The viability of hBMSCs encapsulated in the different hydrogels was not compromised and in conventional in vitro experiments, chondrogenesis was supported by all four hydrogels. Upon culture in the osteochondral biopsy model, hBMSC-alginate constructs cultured in ICM in the osteochondral model resulted in significantly higher Col2 and $A C A N$ gene expression than hBMSC-fibrin 
constructs. These results were supported by the in vivo experiment: implantation of osteochondral biopsies with hBMSC-alginate constructs resulted in significantly more safranin-O positive repair tissue after 12 weeks than was found in biopsies with hBMSC-fibrin constructs. Our findings are in line with findings in the literature: it was reported that upon blending fibrin and alginate, a higher fibrin content was more favourable for hBMSC proliferation, whereas a higher alginate content supported chondrogenesis (Ma et al., 2012). However, no significant differences in DNA content were observed after $28 \mathrm{~d}$ of culture. These findings suggest that conventional in vitro culture might not be sufficiently representative to study the applicability of various hydrogels with hBMSC for cartilage repair.

A possible explanation for the differences between hBMSC-alginate and hBMSC-fibrin constructs after in vivo implantation can be that fibrin allows binding of cells and growth factors to its 3D architecture, where alginate does not interact with cells and only encapsulates them (Weisel, 2005). In previous research, we have found that factors other than TGF $\beta$ secreted by the osteochondral biopsies are capable of inducing chondrogenesis of hBMSCs (de Vries-van Melle et al., 2013). It is possible that upon culture in CCM, the high dosage of TGF $\beta$ circumvented this effect in conventional culture without the osteochondral biopsies.

A point of concern is the integration of newly formed tissue onto the native cartilage and subchondral bone during the 12 weeks of subcutaneous implantation. It is possible that the relatively poor integration was an artefact of processing for histology; the removal of possible hydrogel remnants may have caused slight shrinkage of the newly formed tissue, thereby damaging the fragile attachment onto the native bovine tissue. Another option is that integration was not optimal. Presently there is no way to distinguish these possible explanations.

Interestingly, no beneficial effects on chondrogenesis were observed in hBMSC-alginate/HA constructs. High molecular weight $\mathrm{HA}$ is very viscous, therefore the viscosity of alginate/HA was also higher than that of alginate only. It is possible that the higher viscosity of alginate/HA has compromised the diffusion of nutrients and growth factors into the hBMSC-alginate/HA constructs, thereby decreasing the effectiveness of GAG deposition. Diffusion of nutrients is known to affect the effectiveness of hBMSC chondrogenesis (Farrell et al., 2012). Also, increasing density of HA hydrogels has been shown to negatively affect matrix deposition by hBMSCs (Erickson et al., 2009). Still chondrogenesis took place in alginate/HA, indicated by comparable levels of Col2 and ACAN gene expression after $28 \mathrm{~d}$ of culture in chondrogenic medium for all four hydrogels. Since positive findings were reported for the use of HA both clinically and in laboratory settings (Grigolo et al., 2001; Kavalkovich et al., 2002; Facchini et al., 2006; Liao et al., 2007; Rampichova et al., 2010; Kim et al., 2011; Erickson et al., 2012), we still believe that HA can be beneficial for cartilage tissue engineering purposes, albeit not in the current combination of high molecular weight HA with alginate. Therefore, besides alginate and fibrin, HA-pNIPAM was used to prepare hBMSC-hydrogel constructs in the osteochondral biopsy model. Due to the thermo-responsive nature of HA-pNIPAM, this was found to be very challenging. As mentioned before, HA-pNIPAM is a non-Newtonian liquid that gels for temperatures above $32{ }^{\circ} \mathrm{C}$ and is liquid for temperatures below $32^{\circ} \mathrm{C}$. This poses some practical requirements, such as adequate pre-warming of media and tools that come in contact with hBMSC-HA-pNIPAM constructs. For culture in the osteochondral biopsy system, these requirements were hard to meet, resulting in a successful experiment with hBMSCs from only one donor. Based on this experience, we decided not to use hBMSC-HA-pNIPAM constructs for the in vivo experiment. Apart from this, it is very likely that upon subcutaneous implantation the temperature inside the simulated defects would drop below the required $32{ }^{\circ} \mathrm{C}$, thereby losing the gel-state of the hBMSC-HA-pNIPAM constructs. Given the positive effects on cell viability and chondrogenesis, we believe that HA-pNIPAM could be interesting for cartilage regeneration strategies, despite the technical challenges with its use in our culture systems. Modification of this material making its gelation nonreversible while maintaining its in situ gelation capacity would make the use of this material in our culture system more feasible. Another option would be to study HApNIPAM in orthotopic in vivo models, ensuring the required temperature.

In vitro chondrogenesis of hBMSCs is known to be accompanied by hypertrophy (Pelttari et al., 2006; Pelttari et al., 2008; Hellingman et al., 2011). In strategies aiming for cartilage regeneration, terminal differentiation leading to mineralisation and ultimately to bone formation is undesirable (Farrell et al., 2009; Scotti et al., 2010; Farrell et al., 2011). Relatively high levels of ColX and $A L P L$ gene expression were found in all hydrogels both in normal in vitro culture of hBMSC-hydrogel constructs and in the osteochondral biopsy model. No significant differences between the different hydrogels were observed. Histology for safranin $\mathrm{O}$ and immunohistochemical staining for collagen type 2 after in vitro experiments could provide more information on potential differences in terms of the quality of the formed cartilaginous tissue. However, this is unfortunately not possible since decalcification of osteochondral biopsies is required prior to (immuno) histology. For example, removal of calcium removes the cross-links of alginate, which causes the relatively small amounts of newly formed tissue after the in vitro experiments to fall apart. In vivo bone formation was associated primarily with hBMSC-fibrin constructs, suggesting that alginate prevented the progression of hypertrophy towards terminal differentiation of hBMSCs. Since no bone formation was observed in control defects containing alginate or fibrin without hBMSCs, we can conclude that the observed bone formation in hBMSCfibrin constructs in simulated defects in vivo was formed or induced by hBMSCs. However, it is possible that growth factor binding by fibrin in the osteochondral biopsies was responsible for slower progression of chondrogenesis than in hBMSC-alginate constructs, implying a delay in expression of hypertrophic genes rather than lower expression. 


\section{Conclusion}

The present study revealed important clues for the future development of clinical hBMSC-based cartilage regeneration strategies. This study demonstrates that conventional culture of hydrogel constructs might not be sufficiently representative to study chondrogenesis of hBMSCs in detail. Culture of hBMSC-hydrogel constructs in the more representative joint-like environment provided by the osteochondral biopsies revealed differences in chondrogenic potential of hBMSCs encapsulated in different hydrogels that were confirmed in vivo, indicating that chondrogenesis of hBMSCs is strongly hydrogeldependent. Models providing a representative joint-like environment such as the osteochondral model are of vital importance to gain insight in hBMSC chondrogenesis for the future development of clinical hBMSC-based cartilage regeneration.

\section{Acknowledgements}

The research leading to these results has received funding from the European Union's $7^{\text {th }}$ Framework Programme under grant agreement nos. NMP3-SL-2010-245993 and HEALTH-2007-B-223298, and Science Foundation Ireland (grant number 09/SRC/B1794). The research in this article was performed within the framework of the Erasmus Postgraduate School Molecular Medicine. The authors would like to thank Lizette Utomo for conducting pilot experiments for the present study during her internship as part of the master technical medicine of the University of Twente, Enschede, the Netherlands and Matteo d'Este of the AO Research Institute in Davos for his contribution to the HA-pNIPAM hydrogel data. We wish to confirm that there are no known conflicts of interest associated with this publication and there has been no significant financial support for this work that could have influenced its outcome.

\section{References}

Almqvist KF, Dhollander AA, Verdonk PC, Forsyth R, Verdonk R, Verbruggen G (2009) Treatment of cartilage defects in the knee using alginate beads containing human mature allogenic chondrocytes. Am J Sports Med 37: 1920 1929.

Basta G, Montanucci P, Luca G, Boselli C, Noya G, Barbaro B, Qi M, Kinzer KP, Oberholzer J, Calafiore R (2011) Long-term metabolic and immunological followup of nonimmunosuppressed patients with type 1 diabetes treated with microencapsulated islet allografts: four cases. Diabetes Care 34: 2406-2409.

Bellamy N, Campbell J, Robinson V, Gee T, Bourne R, Wells G (2006) Viscosupplementation for the treatment of osteoarthritis of the knee. Cochrane Database Syst Rev 2: CD005321.

Clockaerts S, Bastiaansen-Jenniskens YM, Feijt C, Verhaar JA, Somville J, De Clerck LS, van Osch GJ (2011) Peroxisome proliferator activated receptor alpha activation decreases inflammatory and destructive responses in osteoarthritic cartilage. Osteoarthritis Cartilage 19: 895902.

D’Este M, Alini M, Eglin D (2012) Single step synthesis and characterization of thermoresponsive hyaluronan hydrogels. Carbohydr Polym 90: 1378-1385.

de Vries-van Melle ML, Mandl EW, Kops N, Koevoet WJ, Verhaar JA, van Osch GJ (2012) An osteochondral culture model to study mechanisms involved in articular cartilage repair. Tissue Eng Part C Methods 18: 45-53.

de Vries-van Melle ML, Narcisi R, Kops N, Koevoet JLM, Bos PK, Murphy JM, Verhaar JAN, van der Kraan PM, van Osch GJVM (2014) Chondrogenesis of mesenchymal stem cells in an osteochondral environment is mediated by the subchondral bone. Tissue Eng Part A 20: 23-33.

Divine JG, Zazulak BT, Hewett TE (2007) Viscosupplementation for knee osteoarthritis: a systematic review. Clin Orthop Relat Res 455: 113-122.

EnobakhareBO, BaderDL, LeeDA(1996)Quantification of sulfated glycosaminoglycans in chondrocyte/alginate cultures, by use of 1,9-dimethylmethylene blue. Anal Biochem 243: 189-191.

Erickson IE, Huang AH, Sengupta S, Kestle S, Burdick JA, Mauck RL (2009) Macromer density influences mesenchymal stem cell chondrogenesis and maturation in photocrosslinked hyaluronic acid hydrogels. Osteoarthritis Cartilage 17: 1639-1648.

Erickson IE, Kestle SR, Zellars KH, Farrell MJ, Kim M, Burdick JA, Mauck RL (2012) High mesenchymal stem cell seeding densities in hyaluronic acid hydrogels produce engineered cartilage with native tissue properties. Acta Biomater 8: 3027-3034.

Facchini A, Lisignoli G, Cristino S, Roseti L, De Franceschi L, Marconi E, Grigolo B (2006) Human chondrocytes and mesenchymal stem cells grown onto engineered scaffold. Biorheology 43: 471-480.

Falanga V, Iwamoto S, Chartier M, Yufit T, Butmarc J, Kouttab N, Shrayer D, Carson P (2007) Autologous bone marrow-derived cultured mesenchymal stem cells delivered in a fibrin spray accelerate healing in murine and human cutaneous wounds. Tissue Eng 13: 1299-1312.

Farndale RW, Sayers CA, Barrett AJ (1982) A direct spectrophotometric microassay for sulfated glycosaminoglycans in cartilage cultures. Connect Tissue Res 9: 247-248.

Farrell E, van der Jagt OP, Koevoet W, Kops N, van Manen CJ, Hellingman CA, Jahr H, O'Brien FJ, Verhaar JA, Weinans H, van Osch GJ (2009) Chondrogenic priming of human bone marrow stromal cells: a better route to bone repair? Tissue Eng Part C Methods 15: 285-295.

Farrell E, Both SK, Odorfer KI, Koevoet W, Kops N, O'Brien FJ, Baatenburg de Jong RJ, Verhaar JA, Cuijpers V, Jansen J, Erben RG, van Osch GJ (2011) In-vivo generation of bone via endochondral ossification by in-vitro chondrogenic priming of adult human and rat mesenchymal stem cells. BMC Musculoskelet Disord 12: 31 .

Farrell MJ, Comeau ES, Mauck RL(2012) Mesenchymal stem cells produce functional cartilage matrix in threedimensional culture in regions of optimal nutrient supply. Eur Cell Mater 23: 425-440. 
Ghidoni I, Chlapanidas T, Bucco M, Crovato F, Marazzi M, Vigo D, Torre ML, Faustini M (2008) Alginate cell encapsulation: new advances in reproduction and cartilage regenerative medicine. Cytotechnology 58: 49-56.

Goa KL, Benfield P (1994) Hyaluronic acid. A review of its pharmacology and use as a surgical aid in ophthalmology, and its therapeutic potential in joint disease and wound healing. Drugs 47: 536-566.

Grigolo B, Roseti L, Fiorini M, Fini M, Giavaresi G, Aldini NN, Giardino R, Facchini A (2001) Transplantation of chondrocytes seeded on a hyaluronan derivative (hyaff-11) into cartilage defects in rabbits. Biomaterials 22: 2417-2424.

Haleem AM, Singergy AA, Sabry D, Atta HM, Rashed LA, Chu CR, El Shewy MT, Azzam A, Abdel Aziz MT (2010) The clinical use of human culture-expanded autologous bone marrow mesenchymal stem cells transplanted on platelet-rich fibrin glue in the treatment of articular cartilage defects: A pilot study and preliminary results. Cartilage 1: 253-261.

Hauselmann HJ, Aydelotte MB, Schumacher BL, Kuettner KE, Gitelis SH, Thonar EJ (1992) Synthesis and turnover of proteoglycans by human and bovine adult articular chondrocytes cultured in alginate beads. Matrix 12: 116-129.

Hellingman CA, Davidson EN, Koevoet W, Vitters EL, van den Berg WB, van Osch GJ, van der Kraan PM (2011) Smad signaling determines chondrogenic differentiation of bone-marrow-derived mesenchymal stem cells: inhibition of Smad1/5/8P prevents terminal differentiation and calcification. Tissue Eng Part A 17: 1157-1167.

Hernandez RM, Orive G, Murua A, Pedraz JL (2010) Microcapsules and microcarriers for in situ cell delivery. Adv Drug Deliv Rev 62: 711-730.

Itay S, Abramovici A, Nevo Z (1987) Use of cultured embryonal chick epiphyseal chondrocytes as grafts for defects in chick articular cartilage. Clin Orthop Relat Res 220: 284-303.

Ito K, Yamada Y, Naiki T, Ueda M (2006) Simultaneous implant placement and bone regeneration around dental implants using tissue-engineered bone with fibrin glue, mesenchymal stem cells and platelet-rich plasma. Clin Oral Implants Res 17: 579-586.

Johnstone B, Hering TM, Caplan AI, Goldberg VM, Yoo JU (1998) In vitro chondrogenesis of bone marrowderived mesenchymal progenitor cells. Exp Cell Res 238: 265-272.

Johnstone B, Alini M, Cucchiarini M, Dodge GR, Eglin D, Guilak F, Madry H, Mata A, Mauck RL, Semino CE, Stoddart MJ (2013) Tissue engineering for articular cartilage repair--the state of the art. Eur Cell Mater 25: 248-267.

Kavalkovich KW, Boynton RE, Murphy JM, Barry F (2002) Chondrogenic differentiation of human mesenchymal stem cells within an alginate layer culture system. In Vitro Cell Dev Biol Anim 38: 457-466.

Kim IL, Mauck RL, Burdick JA (2011) Hydrogel design for cartilage tissue engineering: a case study with hyaluronic acid. Biomaterials 32: 8771-8782.
Liao E, Yaszemski M, Krebsbach P, Hollister S (2007) Tissue-engineered cartilage constructs using composite hyaluronic acid/collagen I hydrogels and designed poly(propylene fumarate) scaffolds. Tissue Eng 13: 537550 .

Liao HT, Chen CT, Chen CH, Chen JP, Tsai JC (2011) Combination of guided osteogenesis with autologous platelet-rich fibrin glue and mesenchymal stem cell for mandibular reconstruction. J Trauma 70: 228-237.

Loeser RF, Carlson CS, McGee MP (1995) Expression of beta 1 integrins by cultured articular chondrocytes and in osteoarthritic cartilage. Exp Cell Res 217: 248-257.

Ma K, Titan AL, Stafford M, Zheng C, Levenston ME (2012) Variations in chondrogenesis of human bone marrow-derived mesenchymal stem cells in fibrin/alginate blended hydrogels. Acta Biomater 8: 3754-3764.

Mackay AM, Beck SC, Murphy JM, Barry FP, Chichester CO, Pittenger MF (1998) Chondrogenic differentiation of cultured human mesenchymal stem cells from marrow. Tissue Eng 4: 415-428.

Malonzo C, Chan SC, Kabiri A, Eglin D, Grad S, Bonel HM, Benneker LM, Gantenbein-Ritter B (2013) A papain-induced disc degeneration model for the assessment of thermo-reversible hydrogel-cells therapeutic approach. J Tissue Eng Regen Med doi: 10.1002/term.1667.

Mortisen D, Peroglio M, Alini M, Eglin D (2010) Tailoring thermoreversible hyaluronan hydrogels by "click" chemistry and RAFT polymerization for cell and drug therapy. Biomacromolecules 11: 1261-1272.

Orive G, Ponce S, Hernandez RM, Gascon AR, Igartua M, Pedraz JL (2002) Biocompatibility of microcapsules for cell immobilization elaborated with different type of alginates. Biomaterials 23: 3825-3831.

Park SH, Choi BH, Park SR, Min BH (2011) Chondrogenesis of rabbit mesenchymal stem cells in fibrin/ hyaluronan composite scaffold in vitro. Tissue Eng Part A 17: $1277-1286$.

Pelttari K, Winter A, Steck E, Goetzke K, Hennig T, Ochs BG, Aigner T, Richter W (2006) Premature induction of hypertrophy during in vitro chondrogenesis of human mesenchymal stem cells correlates with calcification and vascular invasion after ectopic transplantation in SCID mice. Arthritis Rheum 54: 3254-3266.

Pelttari K, Lorenz H, Boeuf S, Templin MF, Bischel O, Goetzke K, Hsu HY, Steck E, Richter W (2008) Secretion of matrix metalloproteinase 3 by expanded articular chondrocytes as a predictor of ectopic cartilage formation capacity in vivo. Arthritis Rheum 58: 467-474.

Peroglio M, Grad S, Mortisen D, Sprecher CM, Illien-Junger S, Alini M, Eglin D (2012) Injectable thermoreversible hyaluronan-based hydrogels for nucleus pulposus cell encapsulation. Eur Spine J 21 Suppl 6: S839849.

Pittenger MF, Mackay AM, Beck SC, Jaiswal RK, Douglas R, Mosca JD, Moorman MA, Simonetti DW, Craig S, Marshak DR (1999) Multilineage potential of adult human mesenchymal stem cells. Science 284: 143-147.

Rampichova M, Filova E, Varga F, Lytvynets A, Prosecka E, Kolacna L, Motlik J, Necas A, Vajner L, 
Uhlik J, Amler E (2010) Fibrin/hyaluronic acid composite hydrogels as appropriate scaffolds for in vivo artificial cartilage implantation. ASAIO J 56: 563-568.

Rokstad AM, Brekke OL, Steinkjer B, Ryan L, Kollarikova G, Strand BL, Skjak-Braek G, Lacik I, Espevik T, Mollnes TE (2011) Alginate microbeads are complement compatible, in contrast to polycation containing microcapsules, as revealed in a human whole blood model. Acta Biomater 7: 2566-2578.

Ryu JH, Kim IK, Cho SW, Cho MC, Hwang KK, Piao H, Piao S, Lim SH, Hong YS, Choi CY, Yoo KJ, Kim BS (2005) Implantation of bone marrow mononuclear cells using injectable fibrin matrix enhances neovascularization in infarcted myocardium. Biomaterials 26: 319-326.

Schmittgen TD, Livak KJ (2008) Analyzing real-time PCR data by the comparative C(T) method. Nat Protoc 3: 1101-1108.

Scotti C, Tonnarelli B, Papadimitropoulos A, Scherberich A, Schaeren S, Schauerte A, Lopez-Rios J, Zeller R, Barbero A, Martin I (2010) Recapitulation of endochondral bone formation using human adult mesenchymal stem cells as a paradigm for developmental engineering. Proc Natl Acad Sci USA 107: 7251-7256.

Thomas S (2000). Alginate dressings in surgery and wound management: Part 3. J Wound Care 9: 163-166.

Ting V, Sims CD, Brecht LE, McCarthy JG, Kasabian AK, Connelly PR, Elisseeff J, Gittes GK, Longaker MT (1998) In vitro prefabrication of human cartilage shapes using fibrin glue and human chondrocytes. Ann Plast Surg 40: $413-420$.

Toole BP (1997) Hyaluronan in morphogenesis. J Intern Med 242: 35-40.

Weisel JW (2005) Fibrinogen and fibrin. Adv Protein Chem 70: 247-299.

Wu X, Ren J, Li J (2012) Fibrin glue as the cell-delivery vehicle for mesenchymal stromal cells in regenerative medicine. Cytotherapy 14: 555-562.

Yoo JU, Barthel TS, Nishimura K, Solchaga L, Caplan AI, Goldberg VM, Johnstone B (1998) The chondrogenic potential of human bone-marrow-derived mesenchymal progenitor cells. J Bone Joint Surg Am 80: 1745-1757.

\section{Discussion with Reviewers}

Reviewer II: The histological images from this model make clear that there is extensive GAG depletion within the native cartilage of the osteochondral biopsies with time.
LDH measurements from your original model description (de Vries-van Melle et al., 2012) suggest that many of the chondrocytes in the bovine cartilage are either dead or dying. Might these changes to the adjacent cartilage be affecting lateral repair tissue integration, as exemplified in Fig. 2B?

Authors: The safranin O-stained sections indeed confirm GAG depletion from the native cartilage. We believe that this phenomenon is due to the lack of mechanical loading. In H\&E-stained sections, the nuclei of the chondrocytes appeared normal, which makes us believe that the cells are still viable. Although the LDH measurements indeed indicate relevant amounts of dead or dying cells, the LDH was not only released from cells in the cartilage, but also from cells in the subchondral bone. The absence of mechanical loading under conditions of poor nutrition (such as during subcutaneous implantation) or the loss of GAG from the adjacent cartilage, could however have affected integration of newly formed tissue onto native cartilage. On the other hand, it is known that poor integration is a relevant problem in the microfracture technique as well as in ACI and its derivatives. This integration definitely deserves further attention in future studies.

Reviewer II: This new model system has the potential to complement other systems for evaluating chondral and osteochondral-tissue repair strategies. However, does the presence of extensive cartilage degradation and continued subchondral bone remodelling within the bovine tissue suggest that your model system better simulates repair within an osteoarthritic joint?

Authors: Preparing the osteochondral biopsies induces tissue injury that can be regarded as traumatic tissue injury that happens in patients. It is known that untreated joint defects are destined to progress towards osteoarthritis (OA). The loss of GAG and the increased remodelling of the subchondral bone in the osteochondral biopsy model are certainly processes that occur in early phases of osteoarthritis as well. Therefore, we believe that our osteochondral biopsy model can indeed be regarded as injured tissue that might represent early osteoarthritis. It would be very interesting to see what mechanical loading would do in this model. It is well known that bone needs mechanical loading to be maintained (Wolffs law) and loading will play a role in development of osteoarthritis and the generation of areas of subchondral bone sclerosis later on. 